\title{
Experience of symptoms indicative of gynaecological cancers in UK women
}

\author{
E L Low ${ }^{1}$, A E Simon ${ }^{*}, 2, \mathrm{~J} \mathrm{Waller}^{1}, \mathrm{~J} \mathrm{Wardle}^{1}$ and U Menon ${ }^{3}$ \\ ${ }^{1}$ Health Behaviour Research Centre, Department of Epidemiology and Public Health, University College London, Gower Street, \\ London WC1E 6BT, UK; ${ }^{2}$ Health Services Research \& Management, A224, College Building, City University London, Northampton \\ Square, London ECIV OHB, UK and ${ }^{3}$ Gynaecological Cancer Research Centre, Institute of Women's Health, University College \\ London, Gower Street, London WC1E 6BT, UK
}

Background: Gynaecological cancers account for 12\% of female cancer incidence in the United Kingdom. Encouraging prompt help-seeking for potential symptoms could help improve outcomes. However, before developing help-seeking interventions, it is important to estimate the number of women with symptoms potentially indicative of a gynaecological cancer to help estimate the impact of such interventions on primary care.

Methods: As part of a face-to-face, population-based survey, women aged $\geqslant 16(n=911)$ were shown a list of symptoms potentially indicative of a gynaecological cancer and were asked to indicate any experienced in the last 3 months. Those who reported symptoms were asked about their responses to one randomly selected index symptom.

Results: Just under half (44\%) of the respondents reported a symptom, with 35\% reporting a frequent and/or severe symptom. Younger $(P<0.001)$, lower socioeconomic status $(P<0.01)$ and non-White women $(P<0.05)$ were significantly more likely to report symptoms. Few (14\%) respondents were both older ( $\geqslant 45$ years) and had a frequent and/or severe symptom. Of these women, 38\% had seen a GP.

Conclusion: Symptoms that potentially indicate a gynaecological cancer, even if limited to those that are frequent and/or severe, appear to be common. Consequently, encouraging prompt help-seeking may increase the burden on primary care. However, targeting those at increased risk (older women with frequent or severe symptoms) should avoid unmanageable increases in primary care consultations for gynaecological conditions.

Gynaecological cancers (uterine, vaginal, cervical, ovarian and vulval cancers) account for around $12 \%$ of new female cancer diagnoses per year in the United Kingdom (UK); (Cancer Research UK, 2012a, 2012b; Office for National Statistics, 2012a) equalling lung cancer and second only to breast cancer diagnoses. One-year survival rates have been argued to be a proxy for late-stage diagnoses (Department of Health, 2007), and there is evidence that 1-year survival rates for gynaecological cancers are significantly lower in England compared with other European countries (Sant et al, 2009; Thomson and Forman, 2009). Recent data from the International Cancer Benchmarking Partnership have also demonstrated lower 1-year survival rates for some cancers (including ovarian) in the UK compared with other countries with similar cancer plans (Coleman et al, 2011).
Data on stage distribution could confirm the hypothesis that these poorer 1-year survival rates are due to higher rates of latestage diagnoses. However, these data are not readily available for all gynaecological cancers in the UK due to the general lack of accurate recording of staging data (Department of Health, 2012). For vaginal and vulval cancers, there are no UK figures on stage distribution, probably due to the relative rarity of these cancers compared with the other three (Cancer Research UK, 2013a). Specific stage-distribution figures for uterine cancer in the UK are also not immediately available, although most cases are diagnosed in the early stages. This could be because of the appearance of easily recognisable symptoms (i.e., post-menopausal bleeding) early in disease progression (Amant et al, 2005). Despite this, given that the difference in survival rate between early- and late-stage

*Correspondence: Dr AE Simon; E-mail: Alice.Simon.1@city.ac.uk

Received 21 February 2013; revised 27 June 2013; accepted 1 July 2013; published online 23 July 2013

(c) 2013 Cancer Research UK. All rights reserved 0007-0920/13 
cancers is wide (85\% for Stage 1 and $25 \%$ for Stage IV (Cancer Research UK, 2013b)), it is argued that any increase in earlier diagnoses may be beneficial.

For cervical cancer, the stage distribution favours early-stage diagnosis, with $75 \%$ of women in the UK diagnosed at FIGO stage I. This is likely to be attributable to the organised population-based screening programme through which the majority of stage I cervical cancers in women aged $<49$ years are diagnosed (NHS Cancer Screening Programmes, 2012). However, around a quarter of women (26\%) in the highest incidence age group (30-39 (Cancer Research UK, 2013c)) are not up to date with screening (Health \& Social Care Information Centre, 2012), and the majority of unscreened women in the age groups $20-34$ and 35-49 are diagnosed with a later stage of cervical cancer (FIGO stage IB +) (NHS Cancer Screening Programmes, 2012). As with uterine cancer, given the differences in survival rates between early- and late-stage cervical cancers (over $99 \%$ at stage Ia1 and $46 \%$ at stage $\mathrm{IVb}$ ) (Benedet et al, 2003), reducing the number of later-stage diagnoses in unscreened women is likely to improve outcomes.

Recent data for ovarian cancer show that despite poorer 1-year survival rates, the proportion of early-stage diagnoses in the UK is comparable to other countries (Maringe et al, 2012). Therefore, it is argued that the lower observed 1-year survival rates are more likely to be a result of poorer management of the women diagnosed at more advanced stages than higher numbers of late diagnoses. Nevertheless, early diagnosis could still improve outcomes for ovarian cancer. For example, the majority of high-grade serous ovarian cancers (HGSCs) (which are included in type II epithelial ovarian cancers; responsible for the majority of all ovarian cancer mortality (Brown and Palmer, 2009)) originate outside the ovaries, spreading to the ovaries as they progress (Gilbert et al, 2012). This results in these tumours becoming advanced-stage early in their development (Cho and Shih, 2009). For type II ovarian cancers, prognosis is influenced by tumour volume, not stage (Kurman et al, 2008), and moving the focus of early diagnosis for ovarian cancer from early stage to detection of low-volume disease in type II cancers, or early diagnosis of HGSCs, could substantially improve outcomes (Gilbert et al, 2012).

There are currently no screening programmes for any gynaecological cancers except cervical, although results of a large randomised controlled trial testing population screening for ovarian cancer are awaited (Menon et al, 2009). Meanwhile, encouraging women with symptoms to consult their general practitioner (GP) promptly is important, particularly, when considering the proportions of women diagnosed with a gynaecological cancer through emergency presentation or by death certificate only (30\% of ovarian, $8 \%$ of uterine and $12 \%$ of cervical cancer diagnoses (National Cancer Intelligence Network, 2010)). Encouragement to seek help could bring these groups into primary care.

However, encouraging prompt symptom presentation and increasing consultation rates might have a significant impact on the primary care workload. Although there is some evidence on which to base estimates of GP consultation levels for gynaecological conditions (Stapley and Hamilton, 2011), it is likely that there is a wider group of women with symptoms who do not currently seek help from their GP. Although these symptoms are unlikely to be cancer, encouraging help-seeking could not only increase earlier cancer diagnoses but also aid in detection of other potentially treatable conditions.

There has been some qualitative research in the United States examining gynaecological cancer symptom awareness and women's responses to symptoms across all five of the cancer types (Cooper et al, 2012) and some research in the UK exploring symptom awareness for individual gynaecological cancers (Low et al, 2012, 2013). However, to our knowledge, there have been no assessments of the population prevalence of symptoms encompassing all gynaecological cancers in UK women, nor have the frequency or severity of symptoms or help-seeking responses been investigated. It is important not only to identify symptoms experienced and responses to these symptoms but also to consider the frequency and severity of symptoms, as symptoms that are frequent or severe are more likely to indicate a gynaecological cancer (Olson et al, 2001; Goff et al, 2004). This is the first study to assess the prevalence of symptoms potentially indicative of a gynaecological cancer, as well the frequency and severity of symptoms and current help-seeking behaviour in response to symptoms.

\section{MATERIALS AND METHODS}

Recruitment. As part of their omnibus survey (which included modules from different contributors, on a range of non-health topics) we commissioned the market research agency, TNS Global (www.tns-ri.co.uk, London), to approach 2173 women (age $\geqslant 16$ years) using stratified random location sampling. Women were invited to complete our survey module using Computer Assisted Personal Interviewing (CAPI) in the presence of trained interviewers in their own homes, in July 2011. Before deciding whether to participate, potential respondents were given written information about the study due to the sensitive nature of the questions. The information explained that the survey contained questions about bodily changes experienced in the last 3 months, including changes in the reproductive system. It made clear that the module was anonymous and confidential, and that respondents who decided to take part were free to withdraw at any time. The interview was conducted in English, and therefore any women who were not fluent in English were excluded. The study was approved by the UCL Research Ethics Committee (ref: 1122/005).

\section{Measures}

Demographics. Respondents were classified as having a higher or lower socioeconomic status (SES) (A, B, C1 vs C2, D, E categories) using the National Readership Survey social grading system (National Readership Survey, 2007). Only 7\% of respondents reported minority ethnicities, so they were grouped together and the sample was categorised as 'White' or 'non-White'. We dichotomised age at 45 years because $85 \%$ of all new cases of gynaecological cancers in the UK are in women aged $\geqslant 45$ years (Cancer Research UK, 2012a, 2012b, 2013b, 2013c, 2013d).

Symptom reporting. Women were presented with a list of 13 symptoms (see Table 2), potentially indicative of a gynaecological cancer (sourced from NHS Choices (NHS Choices, 2013)), and asked, 'In the past 3 months, have you experienced any of the following [symptoms]? (please answer each item with 'yes', or 'no'. If you are not sure, or if the item does not apply to you, answer 'no')'. A 3-month reporting time frame was selected as some symptoms could only be detected following at least two menstrual cycles (e.g., inter-menstrual bleeding). In the analyses, it was not possible to stratify symptoms by gynaecological cancer type as many of the symptoms overlap.

Symptom frequency and severity. Respondents reporting a symptom were asked, 'Please tell us (as far as you remember) how often you experienced [symptom] in the past 3 months'. Response options included: 'Once', 'twice' (both recoded as 'infrequent'), 'several times' and 'all the time' (both recoded as 'frequent'). They were then asked: 'Using the 5-point scale below, please tell us how bad the [endorsed symptom] was on the worst day you had it. If it was as bad as you could imagine it could be, score 5 . If it was not bad at all, score 1. Please remember you can score any 
number from 1 to 5'. Reponses were recoded into 'not severe' (scores 1-3) or 'severe' (score 4 or 5). The frequency and severity questions were repeated for each symptom the respondent reported. For some analyses, we divided respondents into two groups: (i) with a symptom that was severe (score 4 or 5), frequent ('several times' or 'all the time') or both and (ii) with a symptom that was neither frequent nor severe. These questions were similar to those used in other studies exploring frequency and severity of symptoms potentially indicative of a cancer (e.g., Goff et al, 2004).

Help-seeking. To measure help-seeking, we asked, 'Please tell us from the following what, if anything, you did about your [symptom]'. Response options included seeking advice from a pharmacist (chemist); a practice nurse; a GP; going to A\&E (the hospital emergency department); asking for advice from a friend/ relative; looking for advice on the internet; asking/looking for advice somewhere else; using an own remedy/treating it themselves; and waiting to see if it went away/got worse. For each response option, respondents answered 'Yes' or 'No'. Women were only asked about help-seeking for one randomly system-selected symptom, referred to here as the 'index symptom'. The study was designed in this way to avoid the survey becoming so timeconsuming that it would be off-putting to participants.

Analyses. Data were weighted by region, age and SES to achieve a nationally representative female sample and were analysed using SPSS version 18.0 (SPSS Inc., Chicago, IL, USA) (SPSS, 2009). We assessed demographic differences between survey responders and non-responders using $t$-tests and $\chi^{2}$ tests. We used $\chi^{2}$ tests to identify significant demographic differences in symptom reporting and group differences in help-seeking behaviour.

\section{RESULTS}

Sample characteristics. Of the 2173 women who took part in the overall TNS omnibus survey, $911(42 \%)$ completed our survey module. Respondents were aged 16-98, with a mean $(M)$ age of 45 years. When age was dichotomised, 442 women were aged $\geqslant 45$ years and 469 were aged $<45$ years. Most women were White (93\%), married/living as a couple (61\%) and had a high SES (60\%). Responders to our survey module were significantly younger, had a higher SES, were more likely to have a White ethnicity and were more likely to be married or living as a couple than those who refused to complete the module (see Table 1).

Symptom reporting. Just under half of the respondents (44\%, 398/911) reported at least one of the 13 symptoms in our survey $(M=1.2$, range $=0-9)$, with 'pain in the abdomen, lower back or pelvis' (19\%, $n=173)$, 'increased abdominal size' $(17 \%, n=154)$ and 'increased need to go to the toilet' $(15 \%, n=138)$ being the most common (Table 2). The median number of symptoms endorsed was $0(n=513,56 \%)$, with $11 \%$ reporting one symptom $(n=103), 12 \%$ reporting two symptoms $(n=108)$ and $21 \%$ reporting three symptoms or more $(n=187)$. The highest number of symptoms experienced was nine, reported by five women $(0.5 \%)$. Women were more likely to report a symptom indicative of a gynaecological cancer if they were younger (50\% of those under 45 vs $37 \%$ of those aged 45 and over, $\left.\chi^{2}(1,910)=14.87, P<0.001\right)$, had a lower SES (49\% vs $40 \%$ in the higher SES group, $\chi^{2}$ $(1,911)=7.58, P<0.01)$ and were non-White $(58 \%$ vs $43 \%$ in White participants, $\left.\chi^{2}(1,910)=5.64, P<0.05\right)$.

Frequency and severity of symptoms. Overall, $35 \%(n=317 / 911)$ of respondents reported a symptom that was frequent and/or severe, and 9\% (78/911) had a symptom that was neither frequent nor severe. Less than a third $(132 / 442,30 \%)$ of women aged $\geqslant 45$ reported a frequent and/or severe symptom, $14 \%$ of the total
Table 1. Sociodemographic characteristics of responders and nonresponders to the symptom survey module (weighted data, overall $n=2173$ )

\begin{tabular}{|l|c|c|c|}
\hline & $\begin{array}{c}\text { Responders } \\
(\mathrm{n}=911) \\
\mathrm{n} \%\end{array}$ & $\begin{array}{c}\text { Non- } \\
\text { responders } \\
(\mathrm{n}=1262) \\
\mathrm{n} \%\end{array}$ & $\chi^{2}$ (df) \\
\hline Age (mean, (SD), t-test) & $45(17)$ & $49(20)$ & $5.61^{\mathrm{b}}$ \\
\hline
\end{tabular}

Socioeconomic status

\begin{tabular}{|l|l|l|l|}
\hline $\mathrm{ABC} 1$ (higher) & $543(60)$ & $674(53)$ & \\
\hline $\mathrm{C} 2 \mathrm{DE}$ (lower) & $368(40)$ & $588(47)$ & $8.25(1)^{c}$ \\
\hline
\end{tabular}

Ethnicity

\begin{tabular}{|l|c|r|l|}
\hline White & $848(93)$ & $1097(88)$ & \\
\hline Non-white & $62(7)$ & $154(12)$ & $17.69(1)^{\mathbf{b}}$
\end{tabular}

Marital status

\begin{tabular}{|l|c|c|c|}
\hline Single & $204(22)$ & $294(23)$ & \\
\hline $\begin{array}{l}\text { Widowed/divorced/ } \\
\text { separated }\end{array}$ & $149(16)$ & $283(22)$ & \\
\hline Married/living as a couple & $558(61)$ & $676(54)$ & $15.10(2)^{\mathbf{b}}$
\end{tabular}

Reported symptoms

\begin{tabular}{|l|c|c|c|}
\hline At least one & $398(44)$ & - & - \\
\hline None & $513(56)$ & - & - \\
\hline
\end{tabular}

${ }^{a}$ These women took part in the omnibus survey but opted out of our symptom survey module.

$\mathbf{b}_{\text {significant at the } 0.001 \text { level. }}$

${ }^{\mathrm{c}}$ Significant at the 0.01 level.

sample $(n=132 / 911)$ (Table 3$)$. There were no significant demographic differences between the two frequency/severity groups. Individual symptom endorsements by age and frequency and/or severity of symptom are reported in Table 2 .

Help-seeking behaviour. Respondents were asked about helpseeking for a single index symptom. The selection rate for each symptom (expressed as the number of times the symptom was selected as a proportion of the number of times that symptom was endorsed) was fairly similar across symptoms (see Table 2). Just over a third $(36 \%, 142 / 398)$ of respondents who reported a symptom had seen a health-care professional (HCP) (pharmacist, GP, practice nurse, A\&E) about their index symptom, with most $(30 \%, 120 / 398)$ having seen a GP. In symptomatic women, the most common response to the index symptom was to monitor it $(54 \%, 216 / 398)$ and the least common response was to go to $\mathrm{A} \& \mathrm{E}$ $(6 \%, 24 / 398)$. In the sample as a whole, $16 \%(n=142 / 911)$ of women had seen an HCP about their index symptom and $13 \%$ had seen a GP $(n=120 / 911)$.

Of the older $(\geqslant 45$ years) symptomatic women, 37\% $(n=60 /$ $164)$ had seen an HCP and $33 \%(54 / 164)$ had seen a GP. The most common response to a symptom was to monitor it $(49 \%, 81 / 164)$ and the least common response was to visit the A\&E department $(2 \%, 4 / 164)$. Older women were significantly less likely to have asked a friend or relative for advice (14\% vs $28 \%$, $\left.\chi^{2}(1,399)=11.36, P=0.001\right)$ or to have gone to A\&E (2\% vs 9\%, $\left.\chi^{2}(1,398)=6.47, P<0.05\right)$ than younger women. The behaviour patterns remained the same for women with a frequent and severe symptom, although more women had sought medical help, with $42 \%$ having seen an HCP (135/317). 


\begin{tabular}{|c|c|c|c|c|c|c|}
\hline & & \multicolumn{2}{|c|}{$<45$ years $(n=469)$} & \multicolumn{2}{|c|}{$\geqslant 45$ years $(n=442)$} & $(n=398)$ \\
\hline & $\begin{array}{l}\text { Whole sample } \\
\quad(n=911)\end{array}$ & $\begin{array}{l}\text { Frequent } \\
\text { and/ } \\
\text { or severe }\end{array}$ & $\begin{array}{c}\text { Not } \\
\text { frequent } \\
\text { or severe }\end{array}$ & $\begin{array}{c}\text { Frequent } \\
\text { and/ } \\
\text { or severe }\end{array}$ & $\begin{array}{c}\text { Not } \\
\text { frequent } \\
\text { or severe }\end{array}$ & $\begin{array}{c}\text { Chance of selection } \\
\text { over number of } \\
\text { endorsements }\end{array}$ \\
\hline Symptoms endorsed & $n(\%)^{a}$ & $n(\%)^{a}$ & $n(\%)^{a}$ & $n(\%)^{a}$ & $n(\%)^{a}$ & n (\%) \\
\hline Pain in abdomen/lower back/pelvis & $173(19)$ & $81(17)$ & 27 (6) & $55(12)$ & $10(2)$ & $64 / 173(37)$ \\
\hline Increased abdominal size & $154(17)$ & $62(13)$ & $26(6)$ & $45(10)$ & $21(5)$ & $63 / 154(41)$ \\
\hline Increased need to go to the toilet & $138(15)$ & $60(13)$ & $13(3)$ & $51(12)$ & $13(3)$ & 46/138 (33) \\
\hline Increased wind or constipation & $121(13)$ & $42(9)$ & $15(3)$ & $46(10)$ & $17(4)$ & $44 / 121(36)$ \\
\hline Difficulty eating/feeling full quickly & $116(13)$ & $53(11)$ & $14(3)$ & $40(9)$ & $7(2)$ & 49/116 (42) \\
\hline Heavier/longer periods & $107(12)$ & $52(11)$ & $24(5)$ & $23(5)$ & $7(2)$ & $34 / 107(32)$ \\
\hline Pain/discomfort during sex & $83(9)$ & $39(8)$ & $26(6)$ & $11(3)$ & $5(1)$ & $23 / 83(28)$ \\
\hline Itching, pain or soreness of vulva & $64(7)$ & $24(5)$ & $17(4)$ & $18(4)$ & $4(<1)$ & $23 / 64(36)$ \\
\hline Bleeding between periods & $49(5)$ & $17(4)$ & $20(4)$ & $7(2)$ & $4(<1)$ & $17 / 49(35)$ \\
\hline Discharge that smells unpleasant or is blood stained & $44(5)$ & $22(5)$ & $15(3)$ & $7(2)$ & $1(<1)$ & $9 / 44(20)$ \\
\hline Bleeding during/after sex & $31(3)$ & $10(2)$ & $13(3)$ & $1(<1)$ & $6(1)$ & $13 / 31(42)$ \\
\hline Growth/lump/sore/ulcer on skin of vulva & $26(3)$ & $5(1)$ & $11(2)$ & $1(<1)$ & $8(2)$ & $11 / 26(42)$ \\
\hline Bleeding after menopause & $10(1)$ & $1(<1)$ & $3(<1)$ & $0(0)$ & $6(<1)$ & $2 / 10(20)$ \\
\hline
\end{tabular}

Table 3. Symptoms reported by age group $(n=911)$

\begin{tabular}{|l|c|c|c|}
\hline & $\begin{array}{c}\text { Total } \\
\text { sample } \\
(\mathbf{n}=\mathbf{9 1 1})\end{array}$ & $\begin{array}{c}\text { Women } \\
\text { aged } \\
<\mathbf{4 5} \\
(\mathbf{n}=\mathbf{4 6 9 )}\end{array}$ & $\begin{array}{c}\text { Women } \\
\text { aged } \geqslant \mathbf{4 5} \\
(\mathbf{n}=\mathbf{4 4 2})\end{array}$ \\
\hline Did not report symptoms & $\mathbf{n}(\%)$ & $\mathbf{n}(\%)$ & $\mathbf{n}(\%)$ \\
\hline Reported at least one symptom & $\mathbf{3 9 8}(\mathbf{4 4 )}$ & $\mathbf{2 3 4}(\mathbf{5 0})$ & $\mathbf{1 6 4 ( 3 7 )}$ \\
\hline $\begin{array}{l}\text { At least one frequent and/or } \\
\text { severe symptom } \\
\text { No frequent or severe symptoms }\end{array}$ & $317(35)$ & $186(40)$ & $132(30)$ \\
\hline
\end{tabular}

Among the older women ( $\geqslant 45$ years) with an index symptom that was frequent and/or severe (i.e., the most high-risk group), $43 \%(n=56 / 132)$ had seen an HCP and 38\% $(n=50 / 132)$ had seen a GP. These women were most likely to have monitored their symptom $(53 \%, 69 / 132)$ and least likely to have visited A\&E (3\%, $4 / 132)$. Older women with frequent and/or severe symptoms were significantly more likely to have seen a GP (38\% vs $27 \%$, $\left.\chi^{2}(1,397)=5.11, P<0.05\right)$ but significantly less likely to have asked a friend or relative for advice $\left(16 \%\right.$ vs $25 \%, \chi^{2}(1,396)=4.34$, $P<0.05)$ than women who did not fall into this group (see Table 4).

\section{DISCUSSION}

Just under half (44\%) of the women in our sample reported a symptom that may indicate a gynaecological cancer, and for a third $(35 \%)$, the symptom was frequent and/or severe. The rates of GP consultation for potential gynaecological cancer symptoms found here $(13 \%$ of the women in our total sample, $n=120 / 911)$ are somewhat lower than those reported by Stapley and Hamilton
Table 4. Help-seeking for one index symptom among respondents who reported a symptom by risk group $(n=397)$

\begin{tabular}{|c|c|c|c|}
\hline & $\begin{array}{l}\text { Higher- } \\
\text { risk } \\
\text { women } \\
(n=132)\end{array}$ & $\begin{array}{c}\text { Lower- } \\
\text { risk } \\
\text { women } \\
(n=265)\end{array}$ & \\
\hline Response to symptom & $n(\%)$ & $n(\%)$ & $\chi^{2}(\mathrm{df})$ \\
\hline Monitored symptom & $69(53)$ & $147(55)$ & $0.28(1)$ \\
\hline Used own remedy/self-treatment & $59(45)$ & $104(39)$ & $1.08(1)$ \\
\hline Sought help from GP & $50(38)$ & $71(27)$ & $5.11(1)^{a}$ \\
\hline Sought help from internet & $32(25)$ & $79(30)$ & $1.26(1)$ \\
\hline Sought help from friend or relative & $21(16)$ & $67(25)$ & $4.34(1)^{a}$ \\
\hline Sought help from pharmacist & $21(16)$ & $33(12)$ & $0.90(1)$ \\
\hline Sought help from practice nurse & $18(14)$ & $35(13)$ & $0.02(1)$ \\
\hline Sought help from somewhere else & $14(11)$ & $30(11)$ & $0.05(1)$ \\
\hline Sought help from A\&E & $4(3)$ & $20(8)$ & $3.17(1)$ \\
\hline \multicolumn{4}{|c|}{$\begin{array}{l}\text { Higher risk= women aged } \geqslant 45 \text { years with a frequent and/or severe symptom. Lower } \\
\text { risk = women aged }<45 \text { years and women with no frequent or severe symptoms. } \\
{ }^{a} \text { Significant at the } 0.05 \text { level. }\end{array}$} \\
\hline
\end{tabular}

(2011) (20\%). However, analyses on a subsample of our participants aged 16-29 (to allow a comparison with Stapley and Hamilton's (2011) sample) did show similar rates of consultation (21\%; analyses not shown here).

Interestingly, previous research exploring intention to seek help for some of these symptoms in a UK population found that 65$89 \%$ of women said that they would go to their GP within 2 weeks if they had one of these symptoms (Target Ovarian Cancer, 2013). Our survey suggests that, although just under half of UK women may currently have a symptom potentially indicative of a gynaecological cancer $(n=398 / 911)$, only around a third 
( $n=120 / 398,30 \%)$ have sought advice from a GP. This percentage is considerably lower than the percentage of women who said that they would seek help promptly for similar symptoms. This suggests that actual help-seeking may be much lower than anticipated helpseeking and adds weight to the evidence that intention may not be translated into behaviour (Sheeran, 2002). This disparity between intention and behaviour in help-seeking may be due to the influences on help-seeking behaviour in response to an actual symptom (Andersen et al, 2009) that participants may not consider in a hypothetical situation.

Our findings suggest that many more women in the UK have symptoms potentially indicative of a gynaecological cancer than seek help for them. Any successful intervention that encourages women with these symptoms to seek help at primary care level could lead to a considerably increased pressure on the primary care system. However, it may not be appropriate to encourage all women with these symptoms to seek help immediately; for some women, it may be advisable to monitor the symptom in the first instance.

It is likely that the majority of symptomatic women in the current sample did not have a gynaecological cancer, based on the incidence rates for these cancers in the UK population. In the highest-risk age groups for cervical cancer (30-34 and 35-39), we would only expect one case in every 5650 and 6173 women, respectively. In the highest-risk age groups for uterine, ovarian, vulval and vaginal cancers $(70-74,80-84,85+$ and $85+$ respectively), we would only expect to see one case in every $1101,1437,4082$ and 23810 women in the UK, respectively (Office for National Statistics, 2012b). These incidence rates mean that, statistically, we would expect to find less than one case of a gynaecological cancer in our sample of 911 women. Encouraging all of the women in our sample to seek help then may not be appropriate and an alternative course of action may be to target higher-risk groups in any intervention aimed at encouraging women with symptoms to seek help. However, encouraging all women with a symptom they report as frequent and/or severe to seek medical help (whether this symptom indicates cancer or a more benign condition) is likely to be of benefit to the patient in terms of receiving treatment and ameliorating discomfort.

Just over a third of the women in our study (35\%) reported a symptom potentially indicative of a gynaecological cancer that was frequent and/or severe. As some of the symptoms explored in our study are more likely to indicate a gynaecological cancer if they have such characteristics (Olson et al, 2001; Goff et al, 2004), women with these types of symptoms may be at a higher risk of developing a gynaecological cancer. Furthermore, younger women were more likely to report a symptom, whereas most symptoms are more likely to be indicative of cancer in older women (Cancer Research UK, 2012a,b; Office for National Statistics, 2012b). For example, abdominal distension, loss of appetite, abdominal pain and urinary frequency all have higher positive predictive values (PPVs) for ovarian cancer in women aged $\geqslant 55$, compared with younger women (Rossing et al, 2010).

If interventions are not only targeted at women with a frequent and/or severe symptom but also at those who are older, the increase in consultations could be minimised. For example, our data showed that only $14 \%$ of the women surveyed $(n=911)$ were both older $(\geqslant 45$ years $)$ and had a frequent and/or severe symptom, but $5 \%(n=50 / 911)$ had already seen a GP, so around $9 \%(82 / 911)$ of our total sample could be characterised as needing to see their GP urgently. Targeting interventions in this way should ensure that consultations occurring as a result of encouraging earlier help-seeking would be more likely to lead to a cancer diagnosis. In terms of trying to increase early-stage diagnoses of gynaecological cancers, this relatively modest increase in consultations as a result of any successful intervention could potentially be worthwhile.
Limitations. Over half (58\%) of the women who completed the overall omnibus survey did not agree to complete our questions, which raises the issue of whether our results reflect the true prevalence of possible gynaecological cancer symptoms in the population. However, the final sample was broadly representative of the UK female population in terms of ethnicity and SES (Ipsos MediaCT, 2009; Population, Ethnicity, Religion and Migration (PERM), 2009), despite demographic differences between respondents and nonrespondents. Feedback from the interviewers indicated that the reason women gave for refusing or withdrawing was often being embarrassed by the survey content, despite the assured anonymity and the ability to self-complete the survey, suggesting that the data may not be missing at random. It would be difficult to overcome this limitation in any self-report survey with similar content.

Because it is not clear whether embarrassment would be more or less common in women with symptoms, we are unable to speculate about the direction of any possible bias. However, to estimate the impact of the missing data on our findings, we extrapolated the number of women with at least one symptom from our sample $(n=911)$ to a sample including our sample and the nonresponders $(n=2173)$, using the demographic information we had for the non-responders (age, SES, ethnicity and marital status). This showed that the number of women that we would expect to report at least one symptom (based on the demographic structure of the sample including the non-responders) ranged from $43 \%$ to $45 \%$, very similar to the findings in our final sample $(n=911)$. Of course, these estimations do not take into account alternative reasons for non-response, such as having a symptom and feeling too embarrassed to talk about it.

Because of the small numbers of women endorsing each symptom, we analysed all the symptoms together, rather than individually or by cancer type. This meant we did not report findings on help-seeking for individual symptoms or by gynaecological cancer. However, any frequent or severe symptom would be of concern, and it was therefore important to explore help-seeking responses to all symptoms combined.

The exploration of help-seeking for only one randomly selected index symptom was necessary to reduce the overall length of the survey but may have meant that help-seeking was explored for a symptom that was neither frequent nor severe, when that participant may also have had a symptom that was either frequent, severe or both. We ran an additional analysis (not reported here) to explore how many women this applied to. Our analysis showed that 62 women ( $7 \%$ of the total sample) had a mild, infrequent index symptom and also a frequent and/or severe symptom for which help-seeking was not explored.

We felt that it was important to explore the help-seeking behaviour for all symptom types, including the seemingly less-serious symptoms, as this helps to provide a picture of whether people seek help appropriately. However, we acknowledge that it would have been interesting to have had help-seeking data for all of the symptoms endorsed. This could be a consideration for future research.

Finally, the survey did not go through any rigorous reliability and validity testing. Wherever possible, the items drew on previous published work. For example, the frequency and severity questions are similar to those used in a previously published study exploring ovarian cancer symptoms (Goff et al, 2004). However, future studies using similar measurements may benefit from carrying out psychometric testing before use.

\section{CONCLUSIONS}

There is a clear indication that the occurrence of gynaecological symptoms potentially indicative of cancer in women in the UK is substantially higher than recorded in primary care. Our findings 
suggest that the most likely alternative to help-seeking may be to monitor the symptom. However, it may not be appropriate to encourage all women with symptoms to seek help at the primary care level immediately.

Older women were less likely to report a symptom than younger women. Evidence that symptoms are more likely to be indicative of a gynaecological cancer if frequent and/or severe, and that gynaecological cancers are more common at older ages, suggests that targeting interventions towards older women who have a symptom that is frequent or severe could promote appropriate help-seeking without increasing consultations with the 'worried well'.

\section{REFERENCES}

Amant F, Moerman P, Neven P, Timmerman D, Van Limbergen E, Vergote I (2005) Endometrial cancer. Lancet 366(9484): 491-505.

Andersen R, Vedsted P, Olesen F, Bro F, Søndergaard J (2009) Patient delay in cancer studies: a discussion of methods and measures. BMC Health Serv Res 9(1): 189.

Benedet JL, Odicino F, Maisonneuve P, Beller U, Creasman WT, Heintz APM, Ngan HYS, Pecorelli S (2003) Carcinoma of the Cervix Uteri. Int J Gynecol Obstet 83(Supplement 1): 41-48.

Brown PO, Palmer C (2009) The preclinical natural history of serous ovarian cancer: defining the target for early detection. PLoS Med 6(7): e1000114.

Cancer Research UK (2012a) Vaginal cancer statistics http:// www.cancerresearchuk.org/cancer-info/cancerstats/types/vagina/Accessed 22 November 2012.

Cancer Research UK (2012b) Vulval cancer statistics http://www.cancerresearch uk.org/cancer-info/cancerstats/types/vulva/Accessed 18 September 2012.

Cancer Research UK (2013a) UK Cancer Incidence (2010) by Country Summary http://publications.cancerresearchuk.org/cancerstats/ statsincidence/dtinccountries.htmlAccessed 13 June 2013.

Cancer Research UK (2013b) Uterine cancer statistics http://www.cancer researchuk.org/cancer-info/cancerstats/types/uterus/Accessed 6 February 2013.

Cancer Research UK (2013c) Cervical cancer statistics http://www.cancer researchuk.org/cancer-info/cancerstats/types/cervix/Accessed 6 February 2013.

Cancer Research UK (2013d) Ovarian cancer statistics http://www.cancer researchuk.org/cancer-info/cancerstats/types/ovary/Accessed 6 February 2013.

Cho K, Shih I (2009) Ovarian Cancer. Annu Rev Pathol 4: 287-313.

Coleman MP, Forman D, Bryant H, Butler J, Rachet B, Maringe C, Nur U, Tracey E, Coory M, Hatcher J, Mcgahan CE, Turner D, Marrett L, Gjerstorff, Johannesen TB, Adolfsson J, Lambe M, Lawrence G, Meechan D, Morris EJ, Middleton R, Steward J, Richards MA, the ICBP Module 1 Working Group (2011) Cancer survival in Australia, Canada, Denmark, Norway, Sweden, and the UK, 1995-2007 (the International Cancer Benchmarking Partnership): an analysis of population-based cancer registry data. Lancet 377(9760): 127-138.

Cooper C, Polonec L, Stewart S, Gelb C (2012) Gynecologic cancer symptom awareness, concern and care seeking among US women: a multi-site qualitative study. Fam Pract 30(1): 96-104.

Department of Health (2007) Cancer Reform Strategy. Department of Health: London.

Department of Health (2012) Improving Outcomes: A Strategy for Cancer: Second Annual Report 2012Department of Health: London, UK.

Gilbert L, Basso O, Sampalis J, Karp I, Martins C, Feng J, Piedimonte S, Quintal L, Ramanakumar AV, Takefman J, Grigorie MS, Artho G, Krishnamurthy S (2012) Assessment of symptomatic women for early diagnosis of ovarian cancer: results from the prospective DOvE pilot project. Lancet Oncol 13(3): 285-291.

Goff BA, Mandel LS, Melancon CH, Muntz HG (2004) Frequency of symptoms of ovarian cancer in women presenting to primary care clinics. JAMA 291(22): 2705-2712.

Health \& Social Care Information Centre (2012) Cervical Screening Programme-England, 2011-2012. Health \& Social Care Information Centre: London, UK.

Ipsos MediaCT (2009) Social Grade: A Classification Tool. Bite Sized Thought Piece. Ipsos MORI: London, UK.
Kurman R, Visvanathan K, Roden R, Shih L (2008) Early detection and treatment of ovarian cancer: shifting from early stage to minimal volume of disease based on a new model of carcinogenesis. Am J Obstet Gynecol 198(4): 351-356.

Low EL, Simon AE, Lyons J, Romney-Alexander D, Waller J (2012) What do British women know about cervical cancer symptoms and risk factors? Eur J Cancer 48(16): 3001-3008.

Low EL, Waller J, Menon U, Jones A, Reid F, Simon AE (2013) Ovarian cancer symptom awareness and anticipated time to help-seeking for symptoms among UK women. J Fam Plann Reprod Health Care 39(3): 163-171 Published Online First.

Maringe C, Walters S, Butler J, Coleman MP, Hacker N, Hanna L, Mosgaard BJ, Nordin A, Rosen B, Engholm G, Gjerstorff ML, Hatcher J, Johannesen TB, Mcgahan CE, Meechan D, Middleton R, Tracey E, Turner D, Richards MA, Rachet B (2012) Stage at diagnosis and ovarian cancer survival: Evidence from the International Cancer Benchmarking Partnership. Gynecol Oncol 127(1): 75-82.

Menon U, Gentry-Maharaj A, Hallett R, Ryan A, Burnell M, Sharma A, Lewis S, Davies S, Philpott S, Lopes A, Godfrey K, Oram D, Herod J, Williamson K, Seif MW, Scott I, Mould T, Woolas R, Murdoch J, Dobbs S, Amso NN, Leeson S, Cruickshank D, McGuire A, Campbell S, Fallowfield L, Singh N, Dawnay A, Skates SJ, Parmar M, Jacobs I (2009) Sensitivity and specificity of multimodal and ultrasound screening for ovarian cancer, and stage distribution of detected cancers: results of the prevalence screen of the UK Collaborative Trial of Ovarian Cancer Screening (UKCTOCS). Lancet Oncol 10(4): 327-340.

National Cancer Intelligence Network (2010) Route to diagnosis - NCIN data briefing. National Cancer Intelligence Network: London, Uk.

National Readership Survey (2007) Social grade-definitions and discriminatory power. http://www.nrs.co.uk/lifestyle.html (Accessed 19 September 2012).

NHS Cancer Screening Programmes (2012) NHSCSP audit of invasive cervical cancer National report 2007-2011. NHS Cancer Screening Programmes: Sheffield.

Choices NHS (2013) Cancer-NHS Choices. http://www.nhs.uk/conditions/ Cancer/Pages/Introduction.aspx (Accessed 5 June 2013).

Office for National Statistics (2012a) Cancer incidence and mortality in the UK 2007-2009. http://www.ons.gov.uk/ons/rel/cancer-unit/cancer-incidenceand-mortality/2007-2009/stb-cancer-incidence-and-mortality.html (Accessed 22 November 2012).

Office for National Statistics (2012b) Cancer Registrations in England, 2010. http://www.ons.gov.uk/ons/publications/re-reference-tables.html?edition= tcm\%3A77-257416 (Accessed 5 June 2013).

Olson S, Mignone L, Nakraseive C, Caputo T, Barakat R, Harlap S (2001) Symptoms of ovarian cancer. Obstet Gynecol 98(2): 212-217.

Population, Ethnicity, Religion and Migration (PERM) (2009) The non-White ethnic population: by ethnic group, 2009. http://www.ethnicity.ac.uk/ population/size.html (Accessed 31 May 31 2013).

Rossing M, Wicklund K, Cushing-Haugen K, Weiss N (2010) Predictive Value of Symptoms for Early Detection of Ovarian Cancer. J Natl Cancer Inst 102(4): 222-229.

Sant M, Allemani C, Santaquilani M, Knijn A, Marchesi F, Capocaccia R (2009) EUROCARE-4. Survival of cancer patients diagnosed in 1995-1999. Results and commentary. Eur J Cancer 45(6): 931-991.

Sheeran P (2002) Intention-behavior relations: a conceptual and empirical review. ERSP 12(1): 1-36.

Stapley S, Hamilton W (2011) Gynaecological symptoms reported by young women: examining the potential for earlier diagnosis of cervical cancer. Fam Pract 28(6): 592-598.

Target Ovarian Cancer (2013) Target Ovarian Cancer Pathfinder Study 2012. $\mathrm{http} / /$ www.targetovariancancer.org.uk/page.asp?section $=538 \&$ sectionTitle $=$ The $+2012+$ Target + Ovarian + Cancer + Pathfinder + Study\#.UYvDUMqS9CN (Accessed 1 June 2013).

Thomson CS, Forman D (2009) Cancer survival in England and the influence of early diagnosis: what can we learn from recent EUROCARE results. BJC 101(S2): S102-S109.

This work is published under the standard license to publish agreement. After 12 months the work will become freely available and the license terms will switch to a Creative Commons AttributionNonCommercial-Share Alike 3.0 Unported License. 